\title{
Professional Development for Online Teaching: A Literature Review
}

\author{
Heather Leary, Cade Dopp, Chad Turley, Matthew Cheney, \\ Zach Simmons, Charles R. Graham, and Riley Hatch \\ Brigham Young University, Provo, Utah
}

\begin{abstract}
The growth of online learning has created a need for instructors who can competently teach online. This literature review explores the research questions, program recommendations, and future research suggestions related to professional development for online instructors. Articles were selected and coded based on date of publication and the context of the professional development. Results indicate that most research questions focused on (a) professional development programs, (b) instructors, and (c) instructors' online courses. Most program recommendations focused on (a) professional development programs, (b) context of professional development, and (c) instructors' activity during professional development. Future recommendations for research topics focused on professional development programs and instructors, while future recommendations for research methods focused on research design and institutional settings. The findings suggest that while professional development for online instructors is important, consistency in both design and delivery is lacking. Future research is needed to provide guidance to programs, instructors, and institutions leading to satisfaction and success for more online students.
\end{abstract}

Keywords: professional development, teacher development, instructor development, teaching online

Leary, H., Dopp, C., Turley, C., Cheney, M., Simmons, Z., Graham, C.R., \& Hatch, R. (2020).

Professional development for online teaching: A literature review. Online Learning, 24(4), 254-275. https://doi.org/10.24059/olj.v24i4.2198

\section{Professional Development for Online Teaching: A Literature Review}

Over the past decade, online and blended learning have become an integral part of the educational options at many institutions of higher education and many K-12 schools. Large-scale national surveys have shown the consistent growth of online education in the United States for over a decade (Allen \& Seaman, 2013). In fall of 2014 there were 5.8 million distance education students with 2.85 million of those students taking all of their courses online (Allen et al., 2015). This represents "more than one in four students (28\%) taking some of their courses at a distance" 
(Allen et al., 2015, p. 12). That is a healthy number of students taking online courses in a time when distance education is growing.

The increase in student demand for education in online and blended modalities has created a need for instructors who can competently teach online. A national survey conducted in 2016 reported that $39 \%$ of higher education faculty have taught an online course, $43 \%$ have taught a blended course (combining in-person and online teaching) with $81 \%$ of those faculty have converted an in-person course to a blended course, and $37 \%$ of faculty indicated they have taken an online course for credit as a student (Jaschik \& Lederman, 2016). Faculty claim that it takes more effort to teach online than face-to-face (Rhode et al., 2017; Seaman, 2009). Thus, teaching online is likely more difficult because teachers tend to teach the way they were taught (Borup \& Evmenova, 2019; Davis \& Rose, 2007) and lack the experience of being an online student (Jaschik \& Lederman, 2016). While there is some overlap in the skill sets needed to teach in traditional settings and to teach online (Davis \& Roblyer, 2005), it is clear that there are other skills required to teach effectively online (Barbour, 2012; Davis et al., 2007; Easton, 2003).

With the demand for online teachers growing, there is a need to better understand the competencies required for successful online teachers (Ragan et al., 2012). In the past decade, there has been significant work done to develop online teaching competencies for both adult learning (Bigatel et al., 2012; Goodyear et al., 2001; Klein et al., 2004; Muñoz, Sanmamed, \& Sellés, 2013) and K-12 contexts (Dawley et al., 2010; Ferdig et al., 2009; iNACOL, 2011; NEA, 2006; Pulham \& Graham, 2018; SREB, 2006). However, most online teaching competencies don't distinguish between the needs of the novice and the experienced online instructor (Kebritchi et al., 2017). In fact, early online teaching literature focuses primarily on professional development for faculty who are new to online teaching rather than helping the moderately experienced online teacher improve in levels of expertise (Rhode et al., 2017). Current research in the learning sciences (Bransford et al., 2000) as well as in educational technology (Mishra \& Kohler, 2006) point to the idea that many of the most effective pedagogical practices are actually domain-specific. Much of the current online teaching competency work focuses on general pedagogies rather than content-specific pedagogical practices.

With unique competencies required by online instructors, skillfully planned professional development is needed as many instructors are teaching in the online classroom for the first time, while many others are veteran online teachers (Taylor \& McQuiggan, 2008; Vaill \& Testori, 2012). Online instructors face many challenges as they learn to teach using different skills than what is needed in an in-person environment (Alexiou-ray \& Bentley, 2016; Davis et al., 2007). It is not clear to what extent faculty take advantage of the professional development available to them and what aspects of the training are most helpful to their improvement as online instructors. Evidence in the K-12 professional development space found that only $20-38 \%$ of online teachers received professional development prior to teaching online with 28-38\% receiving their training during their first year of teaching (Rice \& Dawley, 2009). Additional research found that only 4\% of responding K-12 teacher preparation programs in the U.S. provided opportunities for field experience in online teaching (Archambault et al., 2016).

The vast majority (81\%) of institutions of higher education offer some kind of formal training $(65 \%)$ or mentoring programs $(59 \%)$ for their online teaching faculty (Allen \& Seaman, 2010). Mohr and Shelton (2017) report that most of these training programs "typically focus on technology, pedagogy, and course content" (p. 134) but are also one-size fits all and thus very general and usually not relevant for the instructor's needs. The formal training comes in a wide 
range of delivery models including workshops, self-teaching, peer mentoring, online modules, and creating a course (Herman, 2012; Meyer \& Murrell, 2014a; 2014b). Understanding the needs of instructors, with identified best practices for teaching about online learning, and how to best use various delivery methods is very important for effective training, but often some if not all of these components are ignored.

While a variety of training is offered in higher education, more recent research found that faculty training is not consistently widespread or designed effectively. One study found $55 \%$ of surveyed faculty designing an online course did not receive any training (Jaschik \& Lederman, 2018), while another study found pedagogical training is limited at many institutions, with $9 \%$ of the institutions surveyed offering no training (Magda et al., 2015). Borup and Evmenova (2019) found that professional development for online teaching might be more effective when designed and modeled for how the online courses to be offered by these instructors might also be designed. Giving instructors the opportunity to be a student in a well-designed online course. Meyer (2014) emphasizes the need to "disentangle the effects of a variety of treatments" to understand what is working and why (Meyer, 2014, p. 102) as well as understanding individual faculty differences and how they influence the needs and perceived effectiveness of professional development programs.

Understanding existing models of professional development and analyzing them for effectiveness could assist the development of new professional development (PD) that maintains the effectiveness of older models while at the same time meets the needs of experienced teachers and the different domains in which they teach. This systematic review of the literature related to online teaching professional development (OTPD) looks deeply across the last two decades of research to understand patterns in what has been learned about OTPD and the questions and issues that continue to be raised about the needs for our future OTPD systems. We expect the outcome of the review to be useful to researchers as well as administrators developing OTPD systems. This literature review was guided by the following research questions:

1. What research questions are being asked/answered related to OTPD?

2. What is the range of best practices in OTPD?

3. What is the curriculum of OTPD programs?

4. What identified research gaps related to OTPD exist in the literature?

\section{Methods}

For this literature review, we searched for and selected manuscripts focused on professional development in online and blended learning. In each article we sought to identify the guiding research questions, professional development curriculum, best practices, recommendations for professional development programs in online learning, and recommendations for further research.

\section{Search Procedure}

The literature search began with primary research in academic journals, dissertations, and books published from 2000 to 2019. We searched in and selected literature from Academic Search Premier, Business Source Premier, Education Full Text, ERIC, Library, Information, Science \& Technology Abstracts with Full Text, MasterFILE Complete, and Professional Development Collection. Search terms in these databases included "professional development", "faculty 
development," "teacher development," or "instructor development" in the abstract. We used Boolean operators to connect these development terms with an online context by searching for "teaching online," "online educat*," "blended class*," "distance educat*," and "hybrid class*." We further refined our search by using Boolean operators to connect our previous terms with educators by searching for "faculty," "professor*," "teacher*," and "instructor*." Our search returned 398 results, of which we reviewed 177 for initial coding. During initial coding we excluded 93 articles because they did not meet our selection criteria. We coded 84 articles from our initial search.

Additional literature was mined from the reference lists of the first set of selected studies during the initial coding process. If a reference appeared to relate to our research questions we searched for the abstract to verify relevancy before adding it to our database.

\section{Selection Procedure and Criteria}

For a manuscript to be included in this literature review, we first inspected the research question(s) addressed in the study. If research questions were not included we checked for the stated purpose of the publication. We determined the source was relevant and should be included if we found a research question or purpose that addressed professional development for people teaching online or blended classes. In the absence of a relevant research question or purpose, the study was included if recommendations for professional development for people teaching in online or blended learning were included. We determined a large number of our search results were not relevant to our study because they addressed online professional development, rather than professional development for people teaching online classes.

The criteria we required for inclusion of an article in our study consisted of date of publication and the context of the professional development within the article. We first ensured that each article was published in the year 2000 or later due to the nature of rapidly advancing technologies within online learning. Furthermore, only articles that dealt with professional development within online academic settings (i.e., K-12, higher education, and continuing education) were included.

\section{Analysis Process}

After selecting the articles for inclusion in our study, we coded the research questions, recommendations for further research, and recommendations for professional development programs using Attride-Stirling's (2001) thematic network analysis technique. Members of the research team individually coded the articles to develop a preliminary coding scheme. The coding schemes involved basic codes of terms found in the research articles (see Figure 1). 
Figure 1. Example research question with highlighted sections of the question and basic codes.

\title{
"What are successful strategies for implementing professional development to prepare and support instructors of online courses? (Storandt 2012)"
}

\author{
Basic codes: \\ Implement PD \\ Prepare Instructors \\ Support Instructors
}

Team members then collaborated and came to consensus on their respective coding schemes. If the basic codes did not align, members re-analyzed them in the article and came to consensus on whether or not the code should be included or excluded. After achieving consensus, members began analysis of the basic codes to determine organizing theme groups for the basic codes (see Figure 2). For example, basic codes such as Student Perceptions, Student Thinking, and Student Views were grouped together with other similar codes to create the organizing theme Student Perceptions. The organizing themes were then analyzed and grouped into larger global themes, such as Students. After completion of this master coding scheme, researchers either recoded the article, or analyzed the codes for patterns in the literature.

Figure 2. Process of grouping basic codes into organizing and global themes.

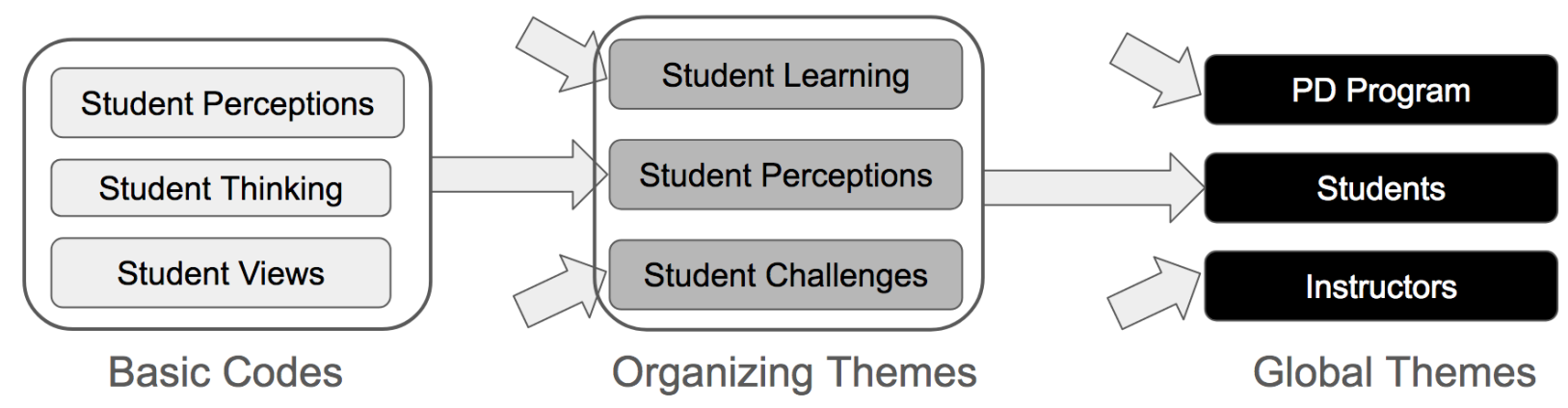

\section{Results}

This section discusses the themes and trends in the literature about professional development for online instructors. Understanding these themes and trends is important when working with instructors teaching online courses, to make improvements to their professional development, and to understand their needs and challenges.

\section{Research Questions Related to Online Teaching Professional Development}

After coding the research questions in the literature (820 total basic codes), the codes were grouped into different categories to aid in synthesizing what current research has explored. The results were the following six global themes: (a) professional development program; (b) instructor; 
(c) instructor's course; (d) students; (e) institution; and (f) other (see Figure 3). Global themes were further subdivided into subthemes (called organizing themes) which provide more specific categorization of global themes. Figure 3 shows the top two organizing themes for each global theme.

Figure 3. Global and top two organizing themes with code counts for research questions related to online teaching professional development.

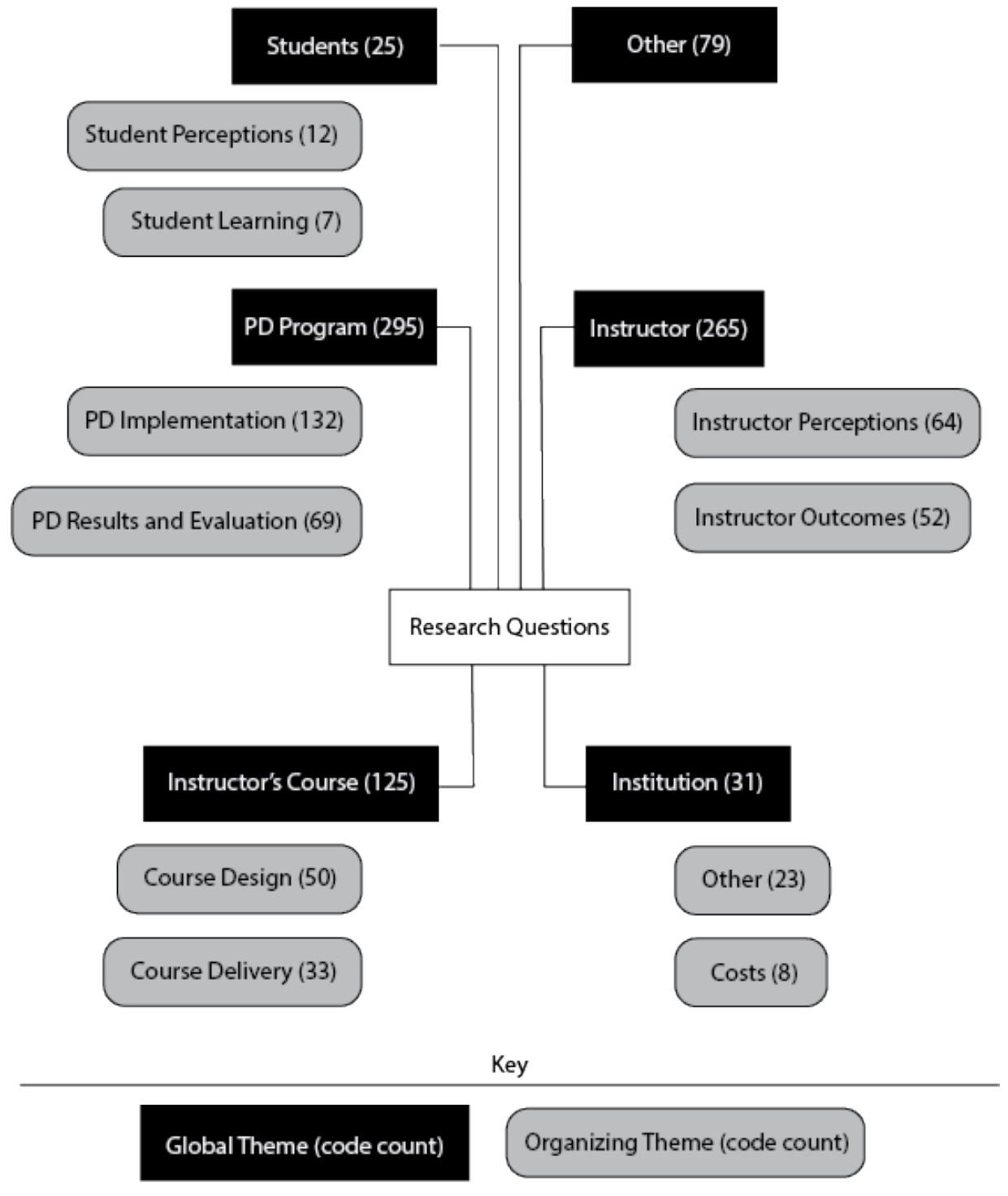

The most common research questions addressed the implementation and evaluation of professional development programs (295 basic codes). Many questions addressed instructors, their needs, perceptions, characteristics, and outcomes (265 basic codes). Fewer questions focused on the instructor course, which included course aspects, design, and delivery (125 basic codes); other ideas relevant, but not critical, to the research such as librarianship, implications, and technical support, that did not fit into any of the other major organizing themes (79 basic codes); the 
institution ( 31 basic codes); and students, their learning, skills, and perceptions (25 basic codes). Table 1 includes details on the top two global themes and accompanying organizing themes and top basic codes for research questions related to online teaching professional development.

Table 1

Top Two Global Themes with Accompanying Organizing Themes and Top Basic Codes for Research Questions Related to Online Teaching Professional Development

\begin{tabular}{|c|c|}
\hline Top Global Themes & $\begin{array}{c}\text { Top Organizing Themes } \\
\bullet \quad \text { Top Basic Codes } \\
\end{array}$ \\
\hline $\begin{array}{l}\text { Professional Development (PD) } \\
\text { Program }\end{array}$ & $\begin{array}{l}\text { PD Implementation } \\
\text { - Timing } \\
\text { - Practices } \\
\text { - Mentoring } \\
\text { - Ongoing Support } \\
\text { PD Results and Evaluation } \\
\text { - PD usefulness } \\
\text { - PD impact } \\
\text { - PD ratings }\end{array}$ \\
\hline Instructor & $\begin{array}{l}\text { Instructor Perceptions } \\
\text { - Instructor Assumptions } \\
\text { - Instructor Recommendations } \\
\text { Instructor Outcomes } \\
\text { - Instructor Satisfaction } \\
\text { - Instructor Learning } \\
\text { Instructor Type } \\
\text { - Staff } \\
\text { - Full-time instructors } \\
\text { Instructor Characteristics } \\
\text { - Instructor Behaviors } \\
\text { - Foundational Knowledge }\end{array}$ \\
\hline
\end{tabular}

Within the professional development program global theme related to research questions explored in the literature, one-third of the codes fell within the organizing theme of professional development implementation, which had 132 total basic codes (see Figure 4). As the largest of the organizing themes, it includes basic codes such as timing, practices, mentoring, ongoing support and further suborganizing themes such as professional development classification, delivery, and format. The second largest organizing theme of PD Results and Evaluation included basic codes of PD usefulness, impact, and ratings. 
Figure 4. Organizing themes with select basic codes within the global theme PD Program related to research questions explored in the literature.

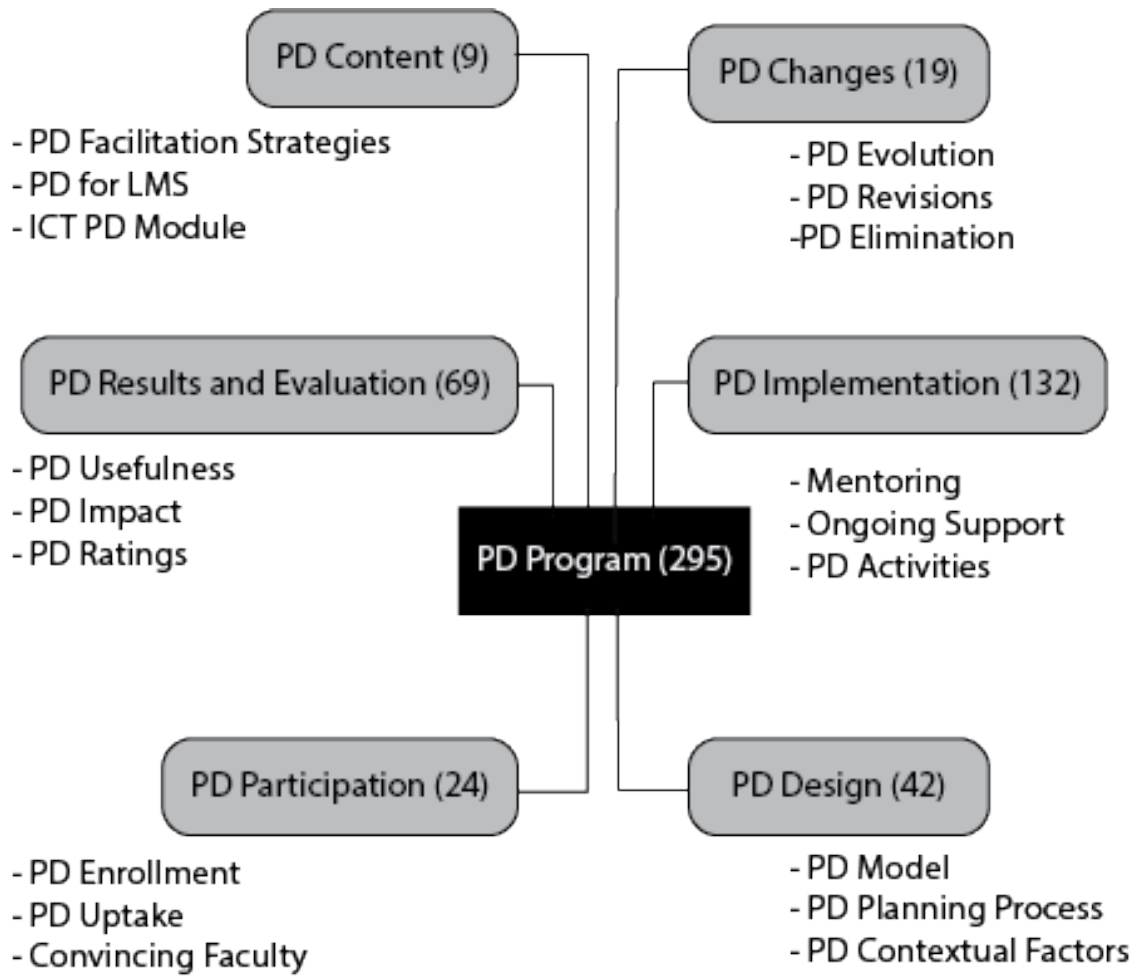

Key

\section{Global Theme (code count)}

Organizing Theme (code count) - Basic Code

In the instructor organizing theme (see Figure 5), the majority of the themes relate to instructor characteristics (type of instructor, knowledge, behavior), instructor perceptions such as their assumptions or recommendations, and instructor outcomes. Very few codes are concerned with any challenges or barriers, concerns, or preferences of the instructors. 
Figure 5. Organizing themes and select basic codes within the global theme instructor.

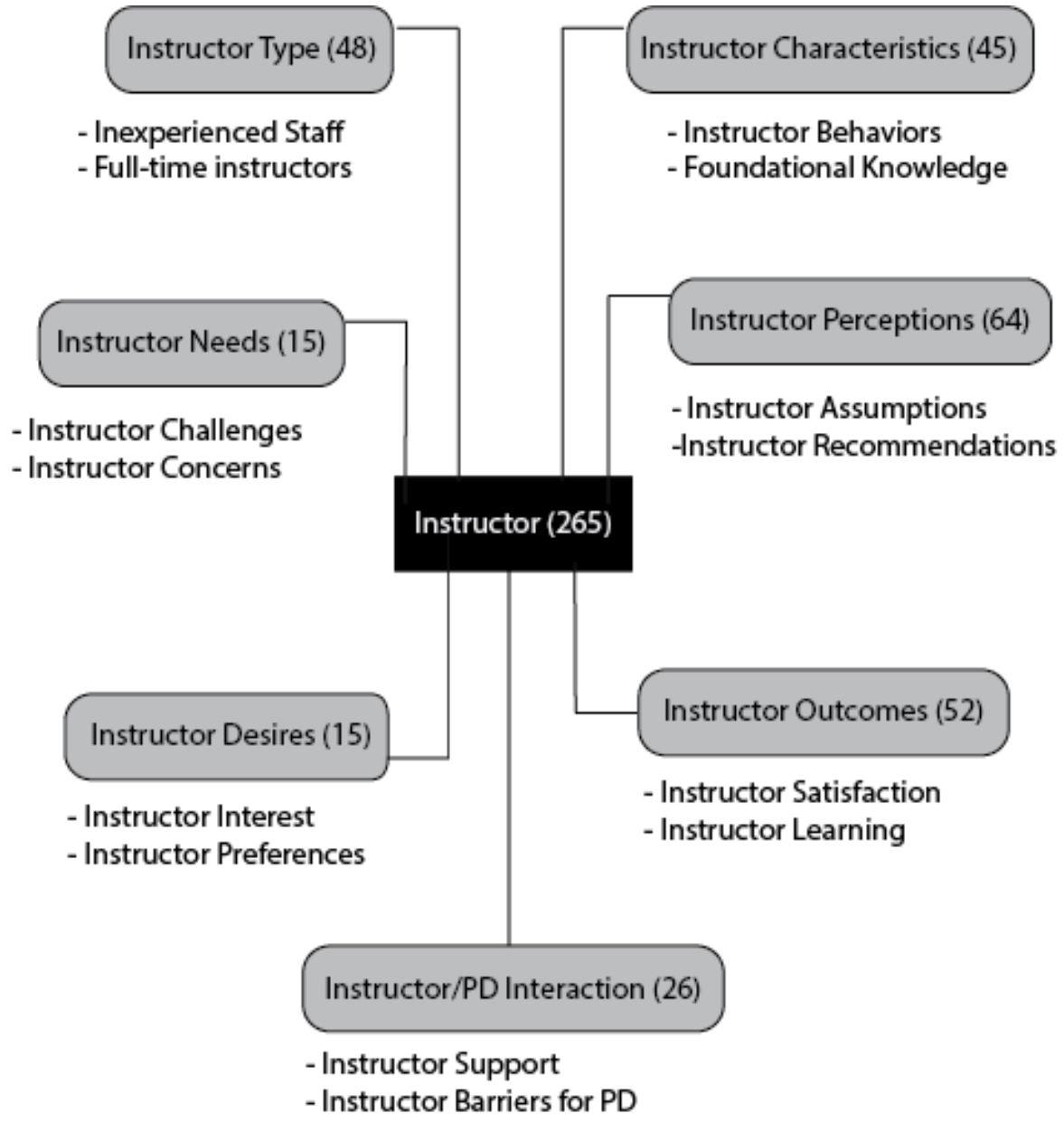

Key

Global Theme (code count)

Organizing Theme (code count)

- Basic Code

\section{Program Recommendations for Professional Development}

To better understand the existing curriculum and professional development practices reported in the literature, themes related to recommendations for professional development programs were coded and organized. Ultimately four global themes of institution, instructor activity during professional development, professional development context, and the professional development program emerged (see Figure 6). 
Figure 6. Global and organizing themes for Program Recommendations.

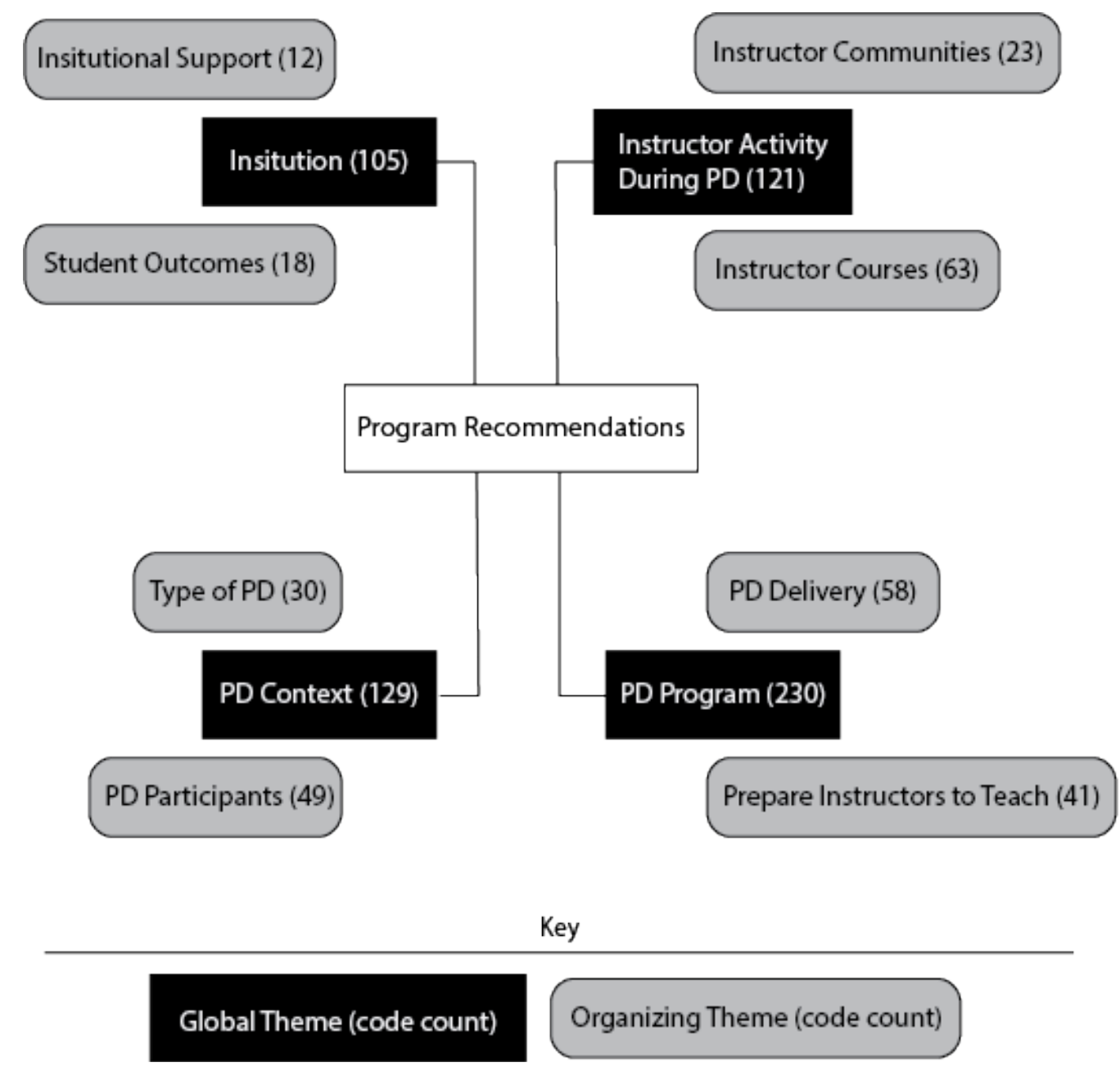

The $P D$ program recommendations global theme (230 basic codes) had almost twice the number of basic codes than the other three global themes (see Figure 7). This theme includes recommendations related directly to the actual PD. Within the organizing themes, there is a broad range of topics within professional development that are suggested and should be emphasized in any professional development program. Of these organizing themes there is a major focus on the delivery of professional development (i.e., workshops, web-based, and asynchronous forum), as well as preparing instructors to teach online (see Table 2). 
Figure 7. Organizing themes and select basic codes for the global theme PD Program, related to program recommendations.

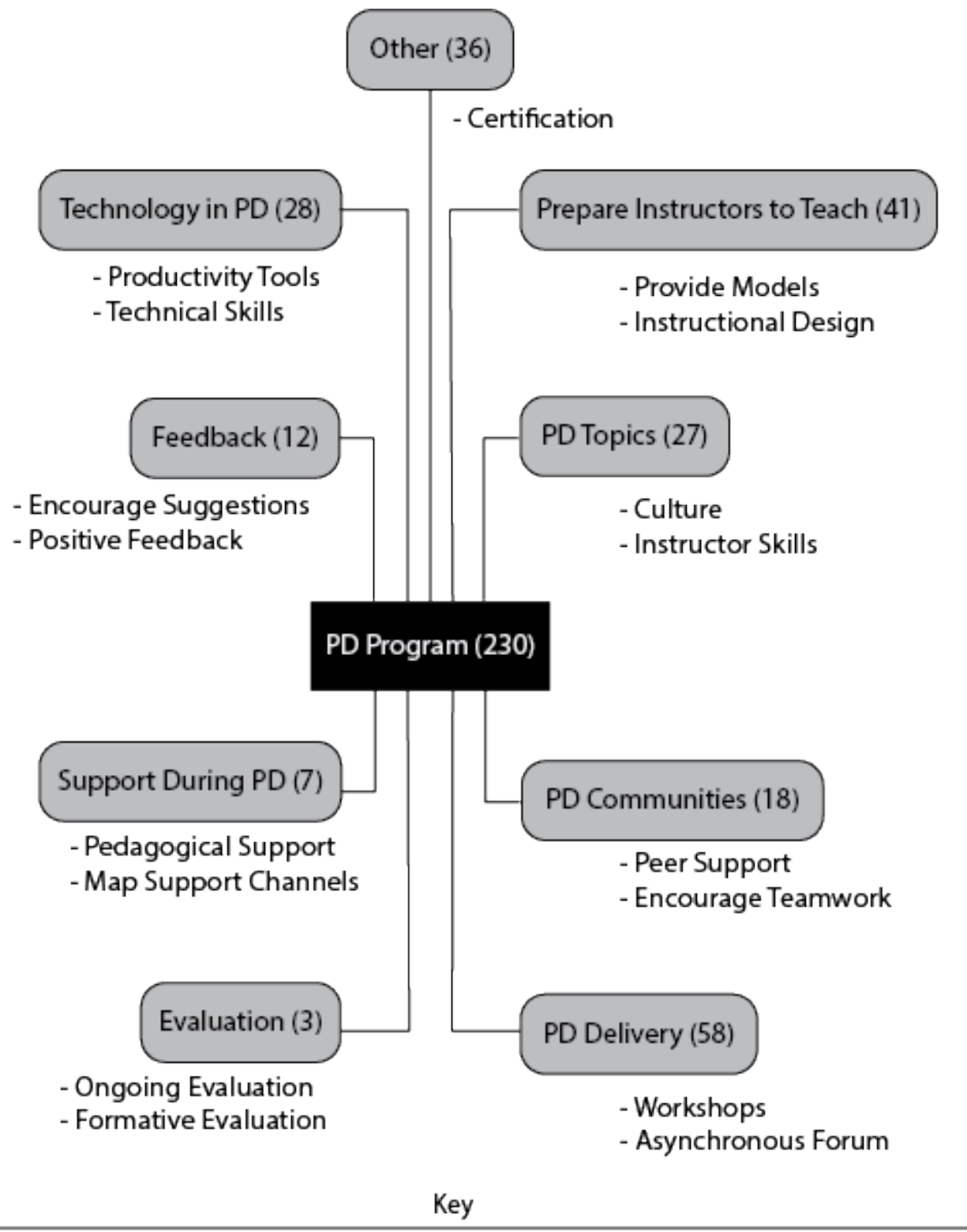


Table 2

The Top Global Theme with Accompanying Top Two Organizing Themes and Basic Codes Related to Recommendations for Professional Development.

\begin{tabular}{ll}
\hline Top Global Theme & $\begin{array}{r}\text { Top Organizing Themes } \\
\text { - }\end{array}$ \\
\hline PD Program & PD Delivery \\
& - Workshops \\
& - Asynchronous Forum \\
& - Web-based \\
& Prepare Instructors to Teach \\
& - Provide Models \\
& - Instructional Design \\
\hline
\end{tabular}

The remaining global themes shared roughly the same amount of total codes. Professional development context (129 basic codes) focused on the context and demographics of professional development. This global theme is related enough with the professional development program global theme to have been placed within it, however, there was enough focus specifically on context to warrant its own global theme. The largest focus in the context global theme is on the participants and tailoring the program to meet the needs of the participants. Furthermore, the type of professional development utilized was mentioned a significant amount within the research. The instructor activity during professional development (121 basic codes) global theme focuses on what instructors should be doing during professional development (i.e., reflection, practicing, designing courses). Beyond this, there is a focus on instructor communities and professional growth for the instructor. Lastly for recommendations for professional development programs is the global theme of institution (105 basic codes) which covers the different institutional aspects of professional development. At the institutional level, there is a focus on student outcomes and logistics of carrying out professional development.

\section{Future Research Related to Online Teaching Professional Development}

Two global themes emerged for grouping the basic codes represented in the literature related to future research (see Figure 8). Research method (56 basic codes) dealt primarily with recommendations as to which settings, design, and who should be included in future research (faculty and staff). The other major theme, research topic (233 basic codes) was recommendations about topics or ideas that should be explored when conducting future research in professional development for online teaching. 
Figure 8. Global and organizing themes with select basic codes for future research.

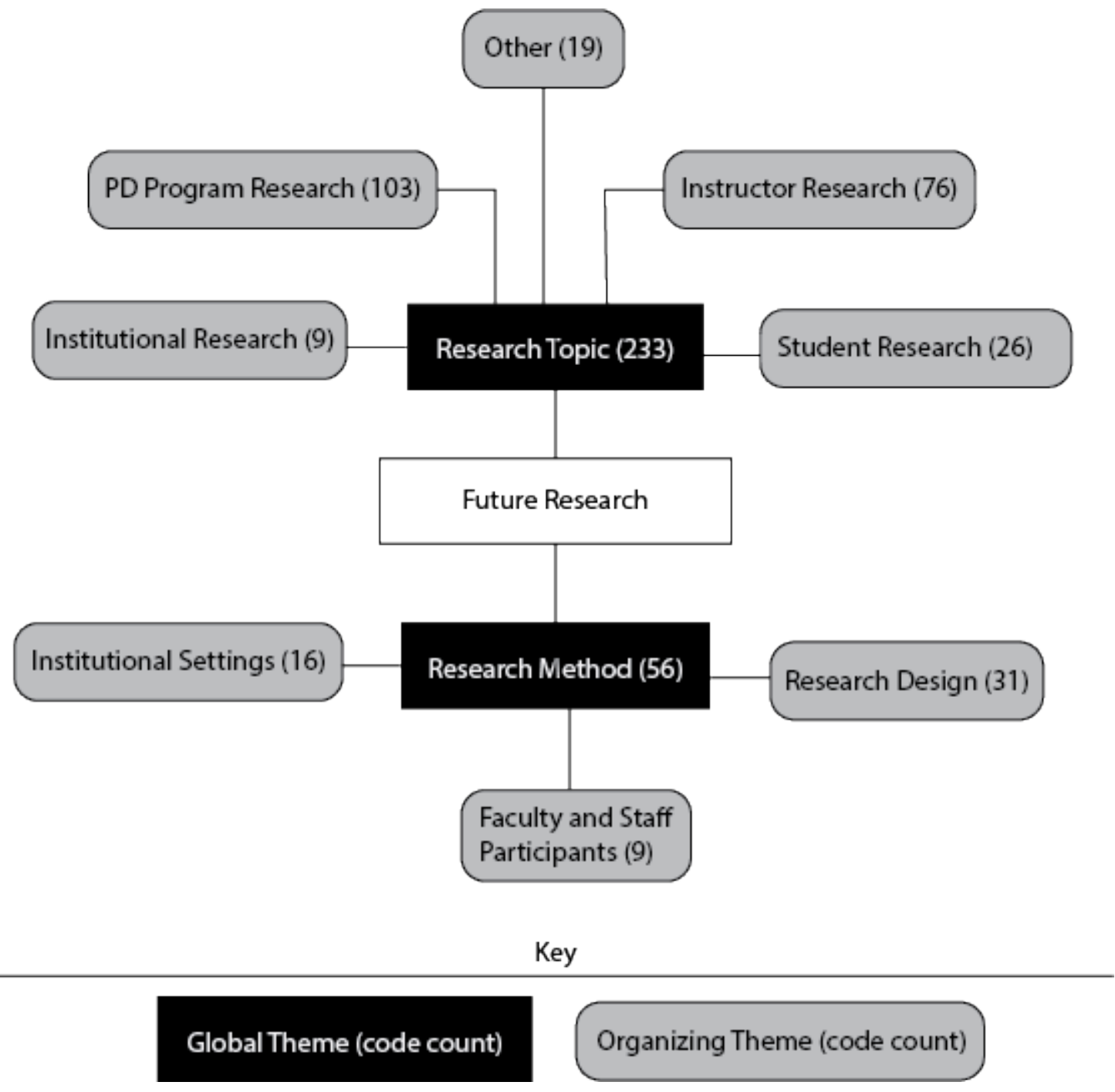

Organizing themes and basic codes helped us understand more of the nuances of what the literature is reporting about their research and future recommendations. Under the research method global theme we included organizing codes at just one level to help interpret all the basic level codes coded directly from the literature. Some of the basic codes represented were case study, qualitative measures, and larger sample size indicating the need for these types of studies or aspects to be considered in the future research design. Faculty and staff participants and institutional settings comprised the rest of the organizing codes. Table 3 reports the two global themes with accompanying top two organizing themes and associated subthemes (if applicable) for future research. 
Table 3

Two Global Themes with Accompanying Top Two Organizing Themes and Associated Suborganizing Themes (if applicable) Related to Future Research

\begin{tabular}{ll}
\hline Top Global Theme & Top Organizing Themes \\
& - Sub-Organizing Themes \\
\hline Research Method & Research Design \\
Institutional Settings \\
Research Topic & PD Program Research \\
& PD Delivery \\
- PD Design \\
- PD Participation \\
- PD Effectiveness \\
Instructor Research \\
- Instructor Demographics \\
- Instructor Characteristics \\
- Instructor Experience \\
- Instructor Concerns \\
\hline
\end{tabular}

Under the research topic global theme we included organizing codes at two different levels to help break down and interpret what the basic codes meant within research topic (see Figure 9). The first level of organizing codes was professional development program research, instructor research, student research, institutional research, and other. There were also nine other second level organizing codes within professional development program research and seven within instructor research. Some of these codes were professional development delivery, professional development design, and professional development effectiveness. Basic codes from the literature made up these second level organizing codes and the other first level organizing codes. An example of this was the first level code professional development program research which had 103 basic levels codes corresponding to it with a second level code professional development delivery, which had 27 basic level codes corresponding to it. Some of the basic level codes were mentoring, forms of training, and professional development methods. 
Figure 9. Global theme, organizing themes, sub-organizing themes, and select basic codes within future research.

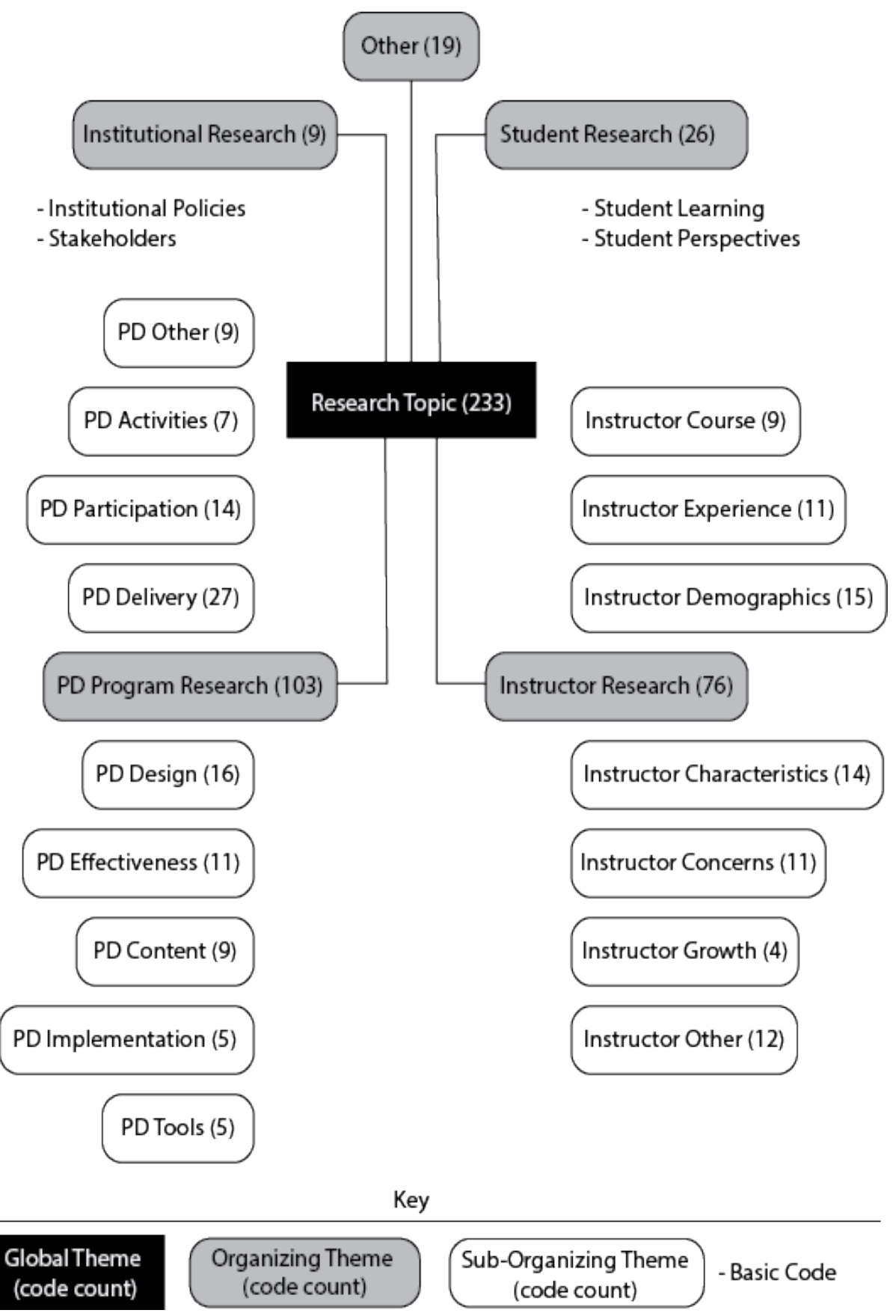




\section{Discussion}

To answer the research questions regarding online teacher professional development research questions, curriculum focus, best practices, and gaps in the literature, literature from the last two decades was explored. We examined the research questions being asked, program recommendations (for best practices and current curricula), and suggested future research recommendations to identify trends related to online teacher professional development. The overall findings of this literature review suggest that many institutions are still investigating online teaching professional development (OTPD) to learn more efficient and effective ways to train online instructors.

Current research questions in the literature have focused on a broad spectrum of topics related to professional development. The overall breadth of codes that make up the research questions help in making assumptions about further research and the importance of what has already been done in online learning and professional development. The highest areas of focus within the research questions related to the PD program itself, implementation, instructors, and helping the instructor design a quality course. We learned from the largest global theme professional development program that exploring and understanding the full spectrum of what a professional development programs entails is important (Meyer, 2014). The codes focus mainly on program implementation and process rather than the setting or the administrative side of professional development. The research questions focused on exploring and understanding professional development programs from design, to content, to implementation, to participants, and evaluation. Areas that did not receive a strong focus included the context or setting, the role of administration, and institutional support and buy-in for the programs.

Another high area focus of research questions was related to instructors. These examined instructor perceptions, outcomes, and characteristics. Interestingly, any references to a student referred to students who will take the course, not the instructor as a student. This is a disconnect for many instructors as it is important for them to understand what it is like to be an online student (Pearcy, 2014; Gregory \& Salmon, 2013). Design and development of professional development programs needs to provide the course instructors with the opportunity to understand the course from the student perspective as well as focus the design for a good student experience and outcomes (Pearcy, 2014; Alexiou-ray \& Bentley, 2016; Gregory \& Salmon, 2013). Related to instructors, the third highest research question tally asked what instructor's courses should contain, including instructional strategies, course quality, and online course conversion.

Among the program recommendations researchers have offered for professional development programs, those related to the program itself, the context of the professional development, instructor's activity during professional development, and institutional recommendations have arisen as the most forthcoming. Interestingly, among these professional development recommendations, professional development programs have received the most attention. This seems to suggest that the PD program itself should be the largest focus of universities seeking to improve professional development at their institutions. Researchers recommend accomplishing this through a focus on the delivery of professional development (Meyer \& Murrell, 2014a; 2014b; Herman, 2012) (web-based, workshops, etc.) and by preparing instructors during professional development programs to effectively teach in their own classrooms (Gregory \& Salmon, 2013). 
Another emerging recommendation stemming from the global theme of professional development context was that the type of professional development and the content within it should rely heavily on the needs of the participants at a given institution (Cobb \& Lowe, 2012; Terosky \& Heasley, 2015). The large emphasis on professional development participants, type of professional development, and tailoring of professional development suggests that professional development should be crafted with these criteria in mind to successfully offer individualized professional development. As far as recommendations for professional development at the institutional level goes, there are a broad range of aspects that are equally important that require attention to create sustainable professional development. These aspects include student outcomes, financial needs, and providing institutional support (Herman, 2012; Meyer, 2014; Ragan et al., 2012).

Under the global theme of instructor activity during professional development, it is recommended that professional development programs offer instruction within the course that can be directly applied within an instructor's course. For example, a professional development course can instruct faculty on designing a course, how to apply theories learned, or effective teaching practices. Furthermore, it is suggested in the research that instructors be given opportunities to reflect on the professional development during the actual professional development course. This reflection could be accomplished by setting aside time for instructors to write in progress journals, set goals, or through creating ePortfolios (Carcioppolo, 2013).

Analysis of the recommendations for future research revealed what current researchers have left out or would find interesting in future studies. To have the research method and the research topic as the overlying themes for what others should consider helps in seeing how broad and untapped the topic of professional development is. Both global themes cover the typical range of topics and methods that one might consider when researching this area, and help to show how much more concerned researchers are with the topic of future research rather than the method by which it is performed.

One of the most interesting findings might be that the design of the research has more weight than the settings or with whom the research is conducted. This theme did have $18 \%$ of the total codes, and merited mentioning in the findings.

The majority of articles under future research topics mention professional development programs as an overall topic to be discussed, but they also suggest a focus on the instructor, student, and institution in connection with professional development. When focused solely on professional development, the largest area of concern is in the delivery of the professional development. Having a focus on the delivery raises some interesting implications seeing as our research is focused on online professional development programs. Some are suggesting that other forms of delivery be considered such as including mentoring, workshops, or informal professional development (Gregory \& Salmon, 2013; Herman, 2012; Vaill \& Testori, 2012). Thus, while much research has been conducted on the methods for professional development programs online, more still needs to be researched on how it is being delivered.

A majority of the other codes under professional development program research focus on how the professional development program is designed, organized, and packaged. The other suborganizing codes may not carry as much weight because they are already being discussed or aren't seen as valuable as the other topics of research. In general, the codes themselves seem to give a 
pretty comprehensive picture and explain the depth in which this research topic has been and will be explored.

Similarly, an organizing theme under research topic that has been fleshed out is instructor research. The second-level organizing codes and basic codes share some insight into understanding the type of instructor that further research should focus on. Current research lacks a comprehensive list (broad range) of instructors, and if other types of instructors were included it could open up new avenues for conducting professional development. Instructors' needs and different courses that they are teaching influence professional development (Davis \& Rose, 2007; Gregory \& Salmon, 2013; Rice \& Dawley, 2009), and thus expanding the search in these areas could help in the further improvement of professional development.

At another level, the students within an instructor's course also inadvertently receive the effects of professional development. Students' concerns, needs, and learning could perhaps be taken into consideration when conducting future research in this area (Meyer, 2014; Meyer \& Murrell, 2014a; Gregory \& Salmon, 2013). The particular emphasis on the student learning alludes to the trickle down that the heads of institutions are hoping will happen with professional development. Perhaps more research needs to be done because if the professional development does not help students learn, then it is not doing its job. A small portion of the codes though such as student research, institutional research, and other show some concerns that other specific researchers have brought up or what like to see addressed.

In all three areas of OTPD explored, research questions, program recommendations, and future research, there appears to be similar global theme focuses on the PD program, instructors, and institution. In the area of PD program similar focuses on program implementation, design, delivery, and evaluation are seen. In the instructor area similar focuses on instructor perceptions, characteristics, and outcomes are seen. There are also similar focuses in the institution area such as financial and administrative policies/structure. This appears to emphasize the need for further research into these areas related to online teacher professional development.

\section{Limitations}

Some limitations to our research could have come from the terms used in naming the codes. Even though we used the specific terms currently used in the literature, there may be some small discrepancies in the classifications of the codes. One code may have not been used in the literature but that term explained what many different excerpts were saying. Some of the organizing themes could have been grouped differently or had different basic codes under them. The other category illustrates this idea and may have a few codes that group well together or within another group depending on one's subjective interpretation.

\section{Conclusion}

Despite the tremendous growth of online learning in both the K-12 and university settings, there appears to be slow growth for development and agreed upon best practices for online teacher professional development programs, instructors, and institutions. With increasing demands for quality K-12 and university instructors, online teacher professional development has a notable role to play. We report that online professional development focuses on teacher; is that where the focus should be? Understanding how to design, deliver, and evaluate professional development, how to best help instructors, and advise institutions are also critical components to the future successes of 
online learning. Unfortunately, there continues to be a struggle with preparing new instructors and supporting experienced instructors for the online environment.

There is a smaller focus in the research questions related to the institution but exploring the role of the institution in online teacher professional development is a strong recommendation in the literature. More program, instructor, and institution-focused future research is needed if we intend to help guide and teach students effectively and efficiently in twenty-first century teaching and learning environments. 


\section{References}

Alexiou-ray, J., \& Bentley, C. C. (2016). Faculty professional development for quality online teaching. Online Journal of Distance Learning Administration, 19(2).

Archambault, L., Kennedy, K., Shelton, C., Dalal, M., McAllister, L. \& Huyett, S. (2016). Incremental progress: Re-examining field experiences in $\mathrm{K}-12$ online learning contexts in the United States. Journal of Online Learning Research, 2(3), 303-326.

Allen I. E., and Seaman, J. (2010). Class differences: Online education in the United States. Babson Survey Research Group.

Allen, I. E., \& Seaman, J. (2013). Changing course: Ten years of tracking online education in the United States. Babson Survey Research Group.

Allen, I. E., Seaman, J., Poulin, R., \& Straut, T. T. (2016). Online report card: Tracking online education in the United States. Babson College Survey Research Group.

Attride-Stirling, J. (2001). Thematic networks: An analytic tool for qualitative research. Qualitative Research, 1(3), 385-405.

Barbour, M. K. (2012). Models and resources for online teacher preparation and mentoring In K. Kennedy \& L. Archambault (Eds.), Lessons learned in teacher mentoring: supporting educators in K-12 online learning environments. International Association for $\mathrm{K}-12$ Online Learning.

Bigatel, P. M., Ragan, L. C., Kennan, S., May, J., \& Redmond, B. F. (2012). The identification of competencies for online teaching success. Journal of Asynchronous Learning Network, 16(1), 59-78.

Borup, J. \& Evmenova, A. S. (2019). The effectiveness of professional development in overcoming obstacles to effective online instruction in a college of education. Online Learning, 23(2), 1-20. doi: 10.24059/olj.v23i2.1468

Bransford, J. D., Brown, A. L., \& Cocking, R. R. (2000). How people learn: Brain, mind, experience, and school. National Academies Press.

Carcioppolo, J. (2013). Designing a phase-based professional development program to improve andragogical effectiveness of faculty teaching online [Doctoral dissertation, Capella University]. ProQuest. (ED No. 553308)

Cobb, C., \& Lowe, D. (2012). Influence of reduced seat time on satisfaction and perception of course development goals: A case study in faculty development. Journal of Asynchronous Learning Networks, 16(2), 85-98.

Davis, N. E., \& Roblyer, M. D. (2005). Preparing teachers for the "schools that technology built": Evaluation of a program to train teachers for virtual schooling. Journal of Research on Technology in Education, 37(4), 399-410.

Davis, N., Roblyer, M. D., Charania, A., Ferdig, R., Harms, C., Compton, L. K. L., \& Cho, M. O. (2007). Illustrating the "virtual" in virtual schooling: Challenges and strategies for creating real tools to prepare virtual teachers. The Internet and Higher Education, 10(1), $27-39$. 
Davis, N., \& Rose, R. (2007). Professional development for virtual schooling and online learning. North American Council for Online Learning. http://www.inacol.org/cms/wpcontent/uploads/2012/11/NACOL_PDforVSandOlnLrng.pdf

Dawley, L., Rice, K., \& Hinck, G. (2010). Going virtual! 2010: The status of professional development and unique needs of K-12 online teachers. Boise State University. https://edtech.boisestate.edu/goingvirtual/goingvirtual3.pdf

Easton, S. S. (2003). Clarifying the instructor's role in online distance learning. Communication Education, 52(2), 87-105. https://doi.org/10.1080/03634520302470

Ferdig, R. E., Cavanaugh, C., DiPietro, M., Black, E., \& Dawson, K. (2009). Virtual schooling standards and best practices for teacher education. Journal of Technology and Teacher Education, 17(4), 479-503.

Goodyear, P., Salmon, G., Spector, J. M., Steeples, C., \& Tickner, S. (2001). Competences for online teaching: A special report. Educational Technology Research and Development, 49(1), 65-72.

Gregory, J., \& Salmon, G. (2013). Professional development for online university teaching. Distance Education, 34(3), 256-270. https://doi.org/10.1080/01587919.2013.835771

Herman, J. H. (2012). Faculty development programs: The frequency and variety of professional development programs available to online instructors. Journal of Asynchronous Learning Networks, 16(5), 87-102.

International Association for K-12 Online Learning (iNACOL). (2011). National standards for quality online courses. http://www.inacol.org/cms/wpcontent/uploads/2013/02/iNACOL_TeachingStandardsv2.pdf

Jaschik, S., \& Lederman, D. (2016). The 2016 Inside Higher Ed survey of faculty attitudes on technology: A study by Gallup and Inside Higher Ed. Gallup.

Jaschik, S., \& Lederman, D. (2018). The 2018 Inside Higher Ed survey of faculty attitudes on technology. Gallup

Kebritchi, M., Lipschuetz, A., \& Santiague, L. (2017). Issues and challenges for teaching successful online courses in higher education: A literature review. Journal of Educational Technology Systems, 46(1), 4-29.

Klein, J. M., Spector, J. M., Grabowski, B., \& de la Teja, I. (2004). Instructor competencies: Standards for face-to-face, online, and blended settings. Information Age Publishing.

Magda, A. J., Poulin, R., \& Clinefelter, D. L. (2015). Recruiting, orienting, \& supporting online adjunct faculty: A survey of practices. The Learning House, Inc.

Meyer, K. A., \& Murrell, V. S. (2014a). A national study of theories and their importance for faculty development for online teaching. Online Journal of Distance Learning Administration, 17(2), 1-19.

Meyer, K. A, \& Murrell, V. S. (2014b). A national study of training content and activities for faculty development for online teaching. Journal of Asynchronous Learning Networks, 18(1), 3-18. 
Meyer, K. A. (2014). An analysis of the research on faculty development for online teaching and identification of new directions. Journal of Asynchronous Learning Networks, 17(4), 93112.

Mishra, P., \& Koehler, M. J. (2006). Technological pedagogical content knowledge: A new framework for teacher knowledge. Teachers College Record, 108(6), 1017-1054.

Mohr, S., \& Shelton, K. (2017). Best practices framework for online faculty professional development: A Delphi study. Online Learning, 21(4), 123-140. doi:10.24059/olj.v21i4.1273

Muñoz Carril, P. C., Sanmamed, M. G., \& Hernández Sellés, N. (2013). Pedagogical roles and competencies of university teachers practicing in the E-learning environment. International Review of Research in Open and Distance Learning, 14(3), 462-487.

National Education Association. (2006). Guide to teaching online courses. National Education Association.

Pearcy, M. (2014). Student, teacher, professor: Three perspectives on online education. History Teacher, 47(2), 169-185.

Pulham, E. B., \& Graham, C. R. (2018). Comparing K-12 online and blended teaching competencies: A literature review. Distance Education, 39(3), 411-432.

Ragan, L., Bigatel, P. M., Kennan, S. S., \& May, D. J. (2012). From research to practice: Towards the development of an integrated and comprehensive faculty development program. Journal of Asynchronous Learning Networks, 16(5), 71-86.

Rhode, J., Richter, S., \& Miller, T. (2017). Designing personalized online teaching professional development through self-assessment. TechTrends, 61(5), 444-451.

Rice, K., \& Dawley, L. (2009). The status of professional development for K-12 online teachers: Insights and implications. Journal of Technology and Teacher Education, 17(4), 523545.

Seaman, J. (2009). Online learning as a strategic asset. Volume II: The paradox of faculty voices-Views and experiences with online learning. ERIC Clearing house. https://books.google.com/books/about/Online_Learning_as_a_Strategic_Asset_Vol.html? id=1AcovwEACAAJ

Southern Regional Education Board. (2006). Standards for quality online teaching (Vol. 30318). Southern Regional Education Board.

Taylor, A., \& McQuiggan, C. A. (2008). Faculty development programming: If we build it, will they come? EDUCAUSE Quarterly, 31(3), 28-37.

Terosky, A. L., \& Heasley, C. (2015). Supporting online faculty through a sense of community and collegiality. Online Learning, 19(3), 147-161.

Vaill, A. L., \& Testori, P. A. (2012). Orientation, mentoring and ongoing support: A three-tiered approach to online faculty development. Journal of Asynchronous Learning Networks, 16(2), 111-119. 